Article

\title{
The Effect of the Thickness of the Sensitive Layer on the Performance of the Accumulating $\mathrm{NO}_{\mathrm{x}}$ Sensor
}

\author{
Andrea Groß ${ }^{1}$, Miriam Richter ${ }^{1}$, David J. Kubinski ${ }^{2}$, Jacobus H. Visser ${ }^{2}$ and Ralf Moos ${ }^{1, *}$ \\ 1 University of Bayreuth, Zentrum für Energietechnik, Lehrstuhl für Funktionsmaterialien, \\ Bayreuth 95440, Germany \\ 2 Ford Research and Advanced Engineering, Dearborn, MI 48124, USA \\ * Author to whom correspondence should be addressed; \\ E-Mail: Functional.Materials@uni-bayreuth.de; Tel.: +49-921-55-7401; Fax:+49-921-55-7405.
}

Received: 2 August 2012; in revised form: 28 August 2012 / Accepted: 31 August 2012 /

Published: 10 September 2012

\begin{abstract}
A novel and promising method to measure low levels of $\mathrm{NO}_{\mathrm{x}}$ utilizes the accumulating sensor principle. During an integration cycle, incoming $\mathrm{NO}_{\mathrm{x}}$ molecules are stored in a sensitive layer based on an automotive lean $\mathrm{NO}_{\mathrm{x}}$ trap (LNT) material that changes its electrical resistivity proportional to the amount of stored $\mathrm{NO}_{\mathrm{x}}$, making the sensor suitable for long-term detection of low levels of $\mathrm{NO}_{\mathrm{x}}$. In this study, the influence of the thickness of the sensitive layer, prepared by multiple screen-printing, is investigated. All samples show good accumulating sensing properties for both $\mathrm{NO}$ and $\mathrm{NO}_{2}$. In accordance to a simplified model, the base resistance of the sensitive layer and the sensitivity to $\mathrm{NO}_{\mathrm{x}}$ decrease with increasing thickness. Contrarily, the sensor response time increases. The linear measurement range of all samples ends at a sensor response of about $30 \%$ resulting in an increase of the linearly detectable amount with the thickness. Hence, the variation of the thickness of the sensitive layer is a powerful tool to adapt the linear measurement range (proportional to the thickness) as well as the sensitivity (proportional to the inverse thickness) to the application requirements. Calculations combining the sensor model with the measurement results indicate that for operation in the linear range, about $3 \%$ of the LNT material is converted to nitrate.
\end{abstract}


Keywords: lean $\mathrm{NO}_{\mathrm{x}}$ trap (LNT); $\mathrm{NO}_{\mathrm{x}}$ storage and reduction catalyst (NSR); low ppm-level $\mathrm{NO}_{\mathrm{x}}$ sensing; semiconducting gas sensor; linear measurement range adaption; carbonate nitrate conversion

\section{Introduction}

Tightened emission and safety regulations have increased the demand for sensitive devices to detect reliably even low levels of $\mathrm{NO}$ and $\mathrm{NO}_{2}\left(\mathrm{NO}_{\mathrm{x}}\right)$ over a long measurement period [1-3] (e.g., summarized as $<100$ ppm $\mathrm{NO}_{\mathrm{x}}$ in the automotive exhaust and 0.5-5 ppm $\mathrm{NO}_{2}$ in the interior by [1]). In the field of automotive or industrial exhausts or of air quality management, the interest is on the accurate determination of mean values (e.g., 1-h value for air quality monitoring [4]) or total amounts (e.g., cumulated vehicle emissions in $\mathrm{g} / \mathrm{km}$ for on-board diagnostics [5,6]) rather than on the curve of the actual instantaneous concentration over time. However, most today's gas sensors measure time-continuously the actual analyte concentration [1]. Cumulated amount mean values are obtained by mathematical averaging (integration). Due to inaccuracies at low analyte levels, long sensor response times and recovery times, as well as due to drifts in the zero point level (baseline), these sensors are subject to errors in the determination of the accumulated analyte levels $[2,3,7]$.

Alternatively the accumulating-type (or integrating-type or dosimeter-type) sensor measures directly the total amounts of analyte gases over a time interval. This novel principle is related to passive samplers being used to determine the cumulated analyte level in two steps. There, over a longer period (e.g., a month) analyte molecules from the ambience are collected in a diffusion controlled process on a sorption material, followed by a quantitative analysis with laboratory gas analysis methods [8,9]. Accumulating-type gas sensors presented here are also based on a sensitive layer that collects analyte molecules over a longer period, but in contrast to passive samplers, the analyte level is evaluated instantaneously and time-continuously by electrical means. While chemically sorbing the analyte molecules, the electrical properties of the sensitive layer, e.g., the resistivity, change with the amount of analyte stored. Like in passive samplers, the sorbent material needs to be regenerated periodically as saturation effects occur. The sensor signal of the accumulating $\mathrm{NO}_{\mathrm{x}}$ sensor correlates directly with the total amount of $\mathrm{NO}_{\mathrm{x}}$ (being the sum of $\mathrm{NO}$ and $\mathrm{NO}_{2}$ ), whereas the curve of the actual concentration can be obtained from the timely derivative of the sensor signal [10]. By collecting analyte molecules from the gas stream, even small levels contribute to the sensor signal, enabling accurate analyte detection over an extended time interval. Another important feature is the fact that errors in the sensor's zero level are minimized since the zero-level is redefined after each regeneration step. Both response times and recovery times of the signal derivative as the measurand for the actual concentration are quite low and in the range of the gas exchange time of the setup $(<7 \mathrm{~s}[10])$. The fast sensing characteristics of the accumulating sensor originate from the fact that the change (i.e., the time-based derivative) in the conductivity during $\mathrm{NO}_{\mathrm{x}}$ exposure correlates with the $\mathrm{NO}_{\mathrm{x}}$ concentration. This is in strong contrast to common gas sensors, in which the equilibrium conductivity of the sensor signal is of interest. In the following, the effect of the thickness of the $\mathrm{NO}_{\mathrm{x}}$ storage layer on the $\mathrm{NO}_{\mathrm{x}}$ accumulating sensing properties is addressed. 


\section{The Accumulating Sensing Concept}

The accumulating or integrating-type sensor is intended to detect directly the total amount, $A$, of low levels of analyte by accumulation. Generally, $A$ can be calculated according to Equation (1) from the analyte concentration, $c(t)$, and the flow rate, $\dot{V}(t)$. Both may vary with time.

$$
A=\int c(t) \cdot \dot{V}(t) \mathrm{d} t
$$

In [11] two setups of the integrating $\mathrm{NO}_{\mathrm{x}}$ sensor are presented. Utilizing a special channel-type setup with a large area of sensitive material compared to the small gas volume inside the channel, all analyte molecules become sorbed and the resulting sensor signal reflects the total amount, $A$, even if the flow rate of the gas varies (amount detector). Contrarily, it was investigated in [11] that by exposing the sensitive layer of the planar device to a large gas volume, always a constant fraction of the analyte molecules in the gas stream is stored independently on the gas flow rate in a wide range. The sensor signal correlates then with the timely integral of the concentration, $\int_{c}(t) \mathrm{d} t$. If the flow rate, $\dot{V}(t)$, remains constant, $A$ is directly proportional to the integral of $c(t)$, i.e., $A \propto \int_{c}(t) \mathrm{d} t$ and the total amount can be determined properly with the planar setup while the signal derivative reflects the curve of $c(t)[10]$.

Figure 1. Planar sensor setup of the impedimetric accumulating $\mathrm{NO}_{\mathrm{x}}$ sensor based on a lean $\mathrm{NO}_{\mathrm{x}}$ trap layer deposited on interdigital electrodes.

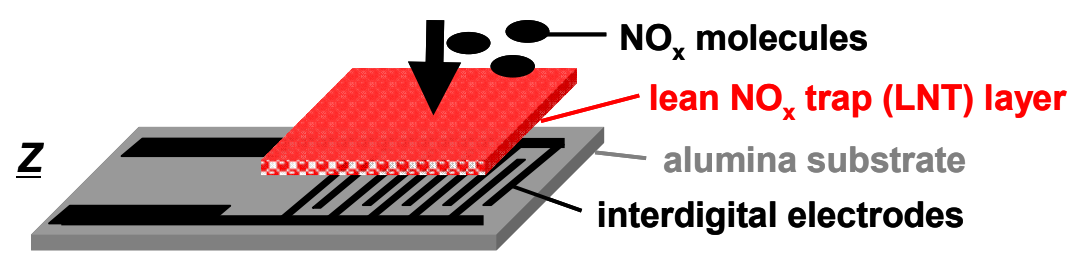

For the accumulating sensing principle sensitive layers of storage materials can be applied. They are able to sorb analyte molecules (e.g., by chemisorption or by a chemical reaction) and thereby they change their electrical properties. As illustrated in Figure 1, the accumulating $\mathrm{NO}_{\mathrm{x}}$ sensor in the planar setup (concentration integrator) consists of a lean $\mathrm{NO}_{\mathrm{x}}$ trap (LNT) layer deposited on an alumina substrate which is equipped with interdigital electrodes (IDEs). It is well known that LNT materials lower their resistivity when transformed from carbonates to nitrates upon $\mathrm{NO}_{\mathrm{x}}$ storage [12-15]. Since the accessible sorption sites in the storage material are becoming occupied with proceeding sorption, saturation effects limit the accumulating properties and a regeneration of the sorption sites is required to recover the original sorption capacity. Therefore, as illustrated in Figure 2(a), in the operation of accumulating sensors the sensing interval during which the sensitive layer (shaded area) accumulates the analyte molecules (black points) from the gas stream alternates with the regeneration interval. The absolute value of the relative resistance change, $R_{\text {rel }}$, calculated by Equation (2) with $R_{0}$ being the base resistance in the unloaded state, is displayed as the accumulating $\mathrm{NO}_{\mathrm{x}}$ sensor signal:

$$
R_{\mathrm{rel}}=\frac{|\Delta R|}{R_{0}}=\frac{R_{0}-R}{R_{0}}
$$


$R_{\text {rel }}$ depends on the loading level which, for low loading states, is proportional to the amount of $\mathrm{NO}_{\mathrm{x}}$ in the gas phase, $A$, as illustrated in Figure 2(b). The sensor signal on the time scale differs from those of conventional gas sensors due to the stepwise $\mathrm{NO}_{\mathrm{x}}$ accumulation. As shown in Figure 2(c), $R_{\text {rel }}$ (black line) increases in the presence of $\mathrm{NO}_{\mathrm{x}}$, whereas it remains constant in the $\mathrm{NO}_{\mathrm{x}}$ absence (holding ability) $-R_{\text {rel }}$ is proportional to $A$ (dark grey line, dotted). In the case of a constant flow rate, $\dot{V}(t)$, the timely increase of the sensor signal is proportional to the $\mathrm{NO}_{\mathrm{x}}$ concentration $c$ (light grey line, right axis). This proportionality enables to determine the curve of the instantaneous concentration using the timely derivative, $\mathrm{d} R_{\text {rel }} / \mathrm{d} t$. In the following, $\mathrm{d} R_{\text {rel }} / \mathrm{d} t$ will be denoted as $\dot{R}_{\text {rel }}$ :

$$
\dot{R}_{\text {rel }}=\frac{\mathrm{d} R_{\text {rel }}}{\mathrm{d} t}
$$

$\dot{R}_{\text {rel }}$ is illustrated as a function of time in Figure 2(d). As depicted in Figure 2(e), there is a linear correlation between $\dot{R}_{\text {rel }}$ and $c$. Hence, to compare the performance of the accumulating sensor with conventional gas sensors, the characteristics of $\dot{R}_{\text {rel }}$ are appropriate. The sensitivity is commonly defined as the slope of the characteristic line which is the correlation between the sensor signal and the measurand [16]. Hence, for the accumulating type $\mathrm{NO}_{\mathrm{x}}$ sensor, which is intended to determine $A$, the amount sensitivity, $S_{\mathrm{A}}$, (Figure 2(b)) can be calculated from the correlation between $R_{\text {rel }}$ and $A$ according to Equation (4) resulting in the unit $\% / \mu \mathrm{L}$. Additionally, in the case of a constant flow rate, the proportionality between $\dot{R}_{\text {rel }}$ and $c$, as shown in Figure 2(e), allows to calculate the concentration sensitivity, $S_{\mathrm{c}}$, according to Equation (5) which is analogous to the sensitivity known of conventional gas sensors:

$$
\begin{gathered}
S_{\mathrm{A}}=\frac{\mathrm{d} R_{\mathrm{rel}}}{\mathrm{d} A} \\
S_{\mathrm{c}}=\frac{\mathrm{d}\left(\mathrm{d} R_{\mathrm{rel}} / \mathrm{d} t\right)}{\mathrm{d} c}=\frac{\mathrm{d} \dot{R}_{\mathrm{rel}}}{\mathrm{d} c}
\end{gathered}
$$

If one transforms Equation (4) using Equation (1), one obtains:

$$
S_{\mathrm{A}}=\frac{\mathrm{d} R_{\mathrm{rel}}}{\mathrm{d} A}=\frac{\mathrm{d} R_{\mathrm{rel}} / \mathrm{d} t}{\mathrm{~d} A / \mathrm{d} t}=\frac{\dot{R}_{\mathrm{rel}}}{\mathrm{d}\left(\int c(t) \cdot \dot{V}(t) \mathrm{d} t\right) / \mathrm{d} t}=\frac{\dot{R}_{\mathrm{rel}}}{\dot{V} \cdot c}
$$

If $S_{\mathrm{c}}=$ const, i.e., $\dot{R}_{\text {rel }} \propto \mathrm{c}$, then $\mathrm{d} \dot{R}_{\text {rel }} / \mathrm{d} c$ can be replaced by $\dot{R}_{\text {rel }} / c$. Then the relation between $S_{\mathrm{c}}$ and $S_{\mathrm{A}}$ yields:

$$
S_{\mathrm{A}}=\frac{1}{\dot{V}} S_{c}
$$

In other words, the amount-related sensitivity, $S_{\mathrm{A}}$, and the "classical" sensitivity with respect to the concentration, $S_{\mathrm{c}}$, are proportional to each other, as long as the gas flow remains constant. As shown in Figure 2(b,e), as soon as saturation effects occur and the linear measurement range, $L M R$, is exceeded, $S_{\mathrm{A}}$ and $S_{\mathrm{c}}$ decrease, and the slope of the signal no longer reflects the concentration (Figure 2(b-e)) the accumulating sensor demands regeneration. 
Figure 2. Scheme of the accumulating sensing principle: (a) Operation with alternating sensing and regeneration periods; (b) characteristic line to determine the total amount: linear correlation between the sensor response and the amount $A$ in the linear measurement range, $L M R$; (c) sensor signal on the time scale, $R_{\text {rel }}$ (black full line), increases in the presence of $\mathrm{NO}_{\mathrm{x}}$; amount $A$ (dotted grey line) calculated acc. to Equation (1); (d) signal derivative $\dot{R}_{\text {rel }}$ reflects the actual concentration $c$; (e) correlation between $\dot{R}_{\text {rel }}$ and $c$.

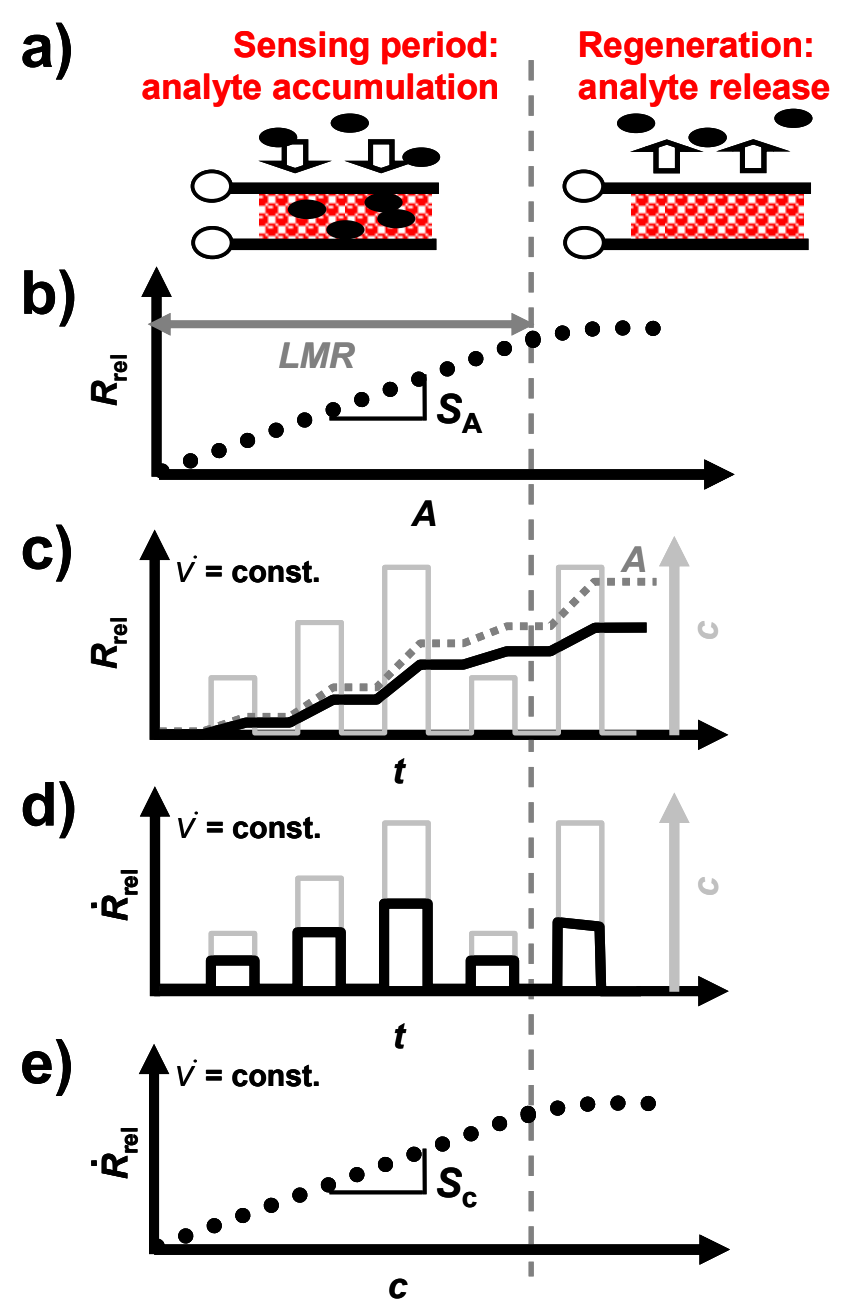

LNT materials are known from automotive $\mathrm{NO}_{\mathrm{x}}$ storage and reduction catalysts to reduce the $\mathrm{NO}_{\mathrm{x}}$ emissions in the exhaust [17-19]. Since $\mathrm{NO}_{\mathrm{x}}$ molecules can be stored in a lean gas atmosphere, whereas they are released and reduced in rich gas compositions, the engine operation cycles between long lean and short rich intervals to ensure low emissions [5,17-19]. LNTs usually consist of alkaline (earth-) oxides or carbonates (e.g., $\mathrm{BaCO}_{3}$ or $\mathrm{K}_{2} \mathrm{CO}_{3}$ ) as storage components, finely dispersed precious metal particles to catalyze oxidation and reduction reactions, and support oxides like $\mathrm{Al}_{2} \mathrm{O}_{3}$ to provide high surface areas for the catalytic processes $[19,20]$. The storage mechanism is based on the conversion of alkaline (earth-) carbonates $\mathrm{MCO}_{3}$ or oxides to nitrates $\mathrm{M}\left(\mathrm{NO}_{3}\right)_{2}$ upon $\mathrm{NO}_{2}$ exposure according to Equation (8). NO needs to be oxidized to $\mathrm{NO}_{2}$ on the catalytic active particles prior to the nitrate formation according to Equation (9) $[17,18,20]$ :

$$
\mathrm{MCO}_{3}+2 \mathrm{NO}_{2}+\frac{1}{2} \mathrm{O}_{2} \leftrightarrow \mathrm{M}\left(\mathrm{NO}_{3}\right)_{2}+\mathrm{CO}_{2}
$$




$$
\mathrm{NO}+\frac{1}{2} \mathrm{O}_{2} \leftrightarrow \mathrm{NO}_{2}
$$

We recently demonstrated the integrating or accumulating $\mathrm{NO}_{\mathrm{x}}$ sensing principle under various gas conditions (base gas composition, temperature) [10,21,22]. Additionally, it was found that the sensitivity to $\mathrm{NO}$ is the same as that to $\mathrm{NO}_{2}$, thus allowing for total $\mathrm{NO}_{\mathrm{x}}$ detection, and that the sensor is suitable for long-term detection of low levels of $\mathrm{NO}_{\mathrm{x}}[10] . \mathrm{O}_{2}$ and $\mathrm{CO}_{2}$ concentration variations were found to be negligible in a wide range in lean gas containing $\mathrm{O}_{2}, \mathrm{CO}_{2}$ and $\mathrm{H}_{2} \mathrm{O}$ [10,21].

In order to understand further how $\mathrm{NO}_{\mathrm{x}}$ storage occurs in the catalyst material, the influence of the thickness of the sensitive layer on the performance of the accumulating $\mathrm{NO}_{\mathrm{x}}$ sensor is the focus of this study. This is motivated by the idea that the number of accessible storage sites and hence the fraction of sites occupied by $\mathrm{NO}_{\mathrm{x}}$ upon $\mathrm{NO}_{\mathrm{x}}$ exposure should depend on the thickness of the LNT coating if the LNT coated area remains the same. The obtained results may even be of interest for LNT catalyst research and may help to elucidate more details about the storage reactions.

\section{Expected Influence of the Thickness of the Sensitive Layer-Some Pre-Considerations}

The storage capacity and hence the number of accessible storage sites control the analyte accumulation properties of LNT catalysts. Hence, it is expected that the thickness of the carbonate layer affects the accumulating sensing properties. As described in Figure 3, a simplified model of the configuration containing the storage material (red) and the interdigital electrodes (black) was developed for a rough estimation of this influence.

Figure 3. Model of the influence of the thickness of the sensitive layer on the electrical properties: (a) Mechanism of the storage of $\mathrm{NO}_{\mathrm{x}}$ as nitrate shells on carbonate cores at the surface of the $\mathrm{NO}_{\mathrm{x}}$ storage layer; (b) simplified electrical model consisting of a parallel circuit of the $\mathrm{NO}_{\mathrm{x}}$ loaded material and the remaining unloaded layer.

\section{a) Scheme of the occupation of $\mathrm{NO}_{x}$ storage sites}

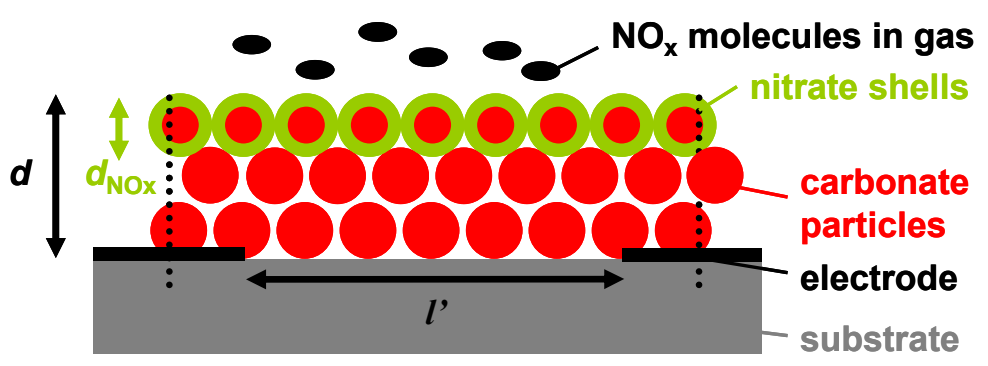

b) Simplified electrical model

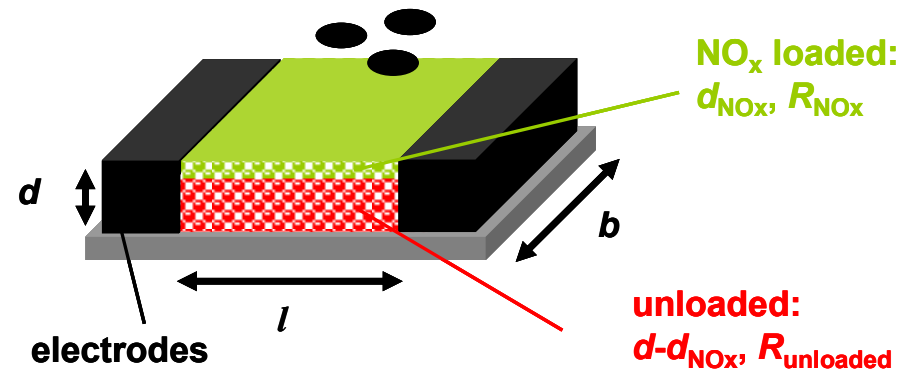


From catalyst research it has been known that $\mathrm{NO}_{\mathrm{x}}$ storage occurs mainly at the surface of the LNT material that is in contact with the gas phase, resulting in less than $40 \%$ utilization of the available storage sites upon saturation [23-25]. This means that even in the highly loaded state, only a fraction of the storage sites are involved in the storage process. Additionally, nitrate formation is accompanied by a shrinking of the pore structure since the nitrates have a higher molar volume than the corresponding carbonates [26]. In the case of $\mathrm{K}_{2} \mathrm{CO}_{3}$, the volume theoretically increases by almost $70 \%$ upon storing $\mathrm{NO}_{\mathrm{x}}$. The decreased diameter of the pores lowers the diffusion of the $\mathrm{NO}_{\mathrm{x}}$ molecules into the carbonate particles and the $\mathrm{NO}_{\mathrm{x}}$ loaded zones can be modeled as dense nitrate shells at the surface of the LNT particles (shrinking core type model [26,27]). Since the accumulating $\mathrm{NO}_{\mathrm{x}}$ sensor is exposed to small $\mathrm{NO}_{\mathrm{x}}$ concentrations and is only operated in the low loading state, nitrate shells are expected to form mainly at the upper surface area of the LNT layer, which is in close contact to the analyte gas phase. Hence, the occupation of $\mathrm{NO}_{\mathrm{x}}$ storage sites in the sensitive layer by $\mathrm{NO}_{\mathrm{x}}$ molecules can be illustrated as shown in Figure 3(a). Thereby, the thickness of the $\mathrm{NO}_{\mathrm{x}}$ loaded area, $d_{\mathrm{NOx}}$, increases with progressive $\mathrm{NO}_{\mathrm{x}}$ exposure. If the distance between the electrodes, $l$ ', is much larger than the film thickness, $d$, the electrical field lines between the electrode fingers are parallel and homogenously distributed. Almost the entire flux is inside the material [28]. Hence, in a simplified model of the sensor setup, the LNT layer can be described as a resistive material in between two parallel electrodes with the distance $l$ (Figure 3(b)). The term $l$ is related to the distance of the planar electrodes of the IDEs, $l$ '. The relation between $l$ and $l$ ' can be calculated which has even been experimentally proven in [29].

Applying this simplified model of Figure 3(b) for the case of the regenerated state $\left(d_{\mathrm{NOx}}=0\right)$, the base resistance of the accumulating $\mathrm{NO}_{\mathrm{x}}$ sensor in the unloaded state, $R_{0}$, can be calculated from the geometry and the resistivity of the carbonate material, $\rho_{0}$, by Equation (10). Therefore, it is expected that $R_{0}$ correlates with the inverse thickness, $1 / d$ :

$$
R_{0}=\rho_{0} \frac{l}{b d} \propto \frac{1}{d}
$$

Upon exposure to $\mathrm{NO}_{\mathrm{x}}$, it is assumed that surface nitrate is formed. Hence, the corresponding simplified model in the partly loaded state contains a thin nitrate film with the resistance $R_{\mathrm{NOx}}$ and the thickness $d_{\text {NOx }}$ on top of the remaining unloaded material with the resistance $R_{\text {unloaded, }}$ as shown in Figure 3(b). The resulting resistance of the sensitive layer, $R$, can be calculated as a parallel circuit of both fractions $\left(R_{\mathrm{NOx}} \| R_{\text {unloaded }}\right)$. The sensor signal $R_{\text {rel }}$ can then be calculated from the sensor geometry, the resistivity of the sensitive material in the unloaded state, $\rho_{0}$, and the resistivity of the $\mathrm{NO}_{\mathrm{x}}$ loaded material, $\rho_{\mathrm{NOx}}$, according to Equation (11):

$$
R_{\mathrm{rel}}=\frac{|\Delta R|}{R_{0}}=\frac{1}{\frac{d}{d_{N O x}\left(\rho_{0} / \rho_{\mathrm{NOx}}-1\right)}+1}
$$

$d_{\text {NOx }}$ can be assumed to be very small compared to the thickness of the sensitive layer, $d$, since only the lightly loaded state is considered. If it is further considered that the resistivity decreases by at least one order of magnitude in the presence of $\mathrm{NO}_{\mathrm{x}}$, Equation (11) can be simplified to Equation (12) meaning that $R_{\text {rel }}$ is proportional to $1 / d$ : 


$$
R_{\mathrm{rel}} \approx \frac{d_{\mathrm{NOx}} \cdot\left(\rho_{0} / \rho_{\mathrm{NOx}}-1\right)}{d} \propto \frac{1}{d}
$$

Since $A$ is independent of $d$ and the same amount of $\mathrm{NO}_{\mathrm{x}}$ is expected to result in the same thickness of the formed $\mathrm{NO}_{\mathrm{x}}$ loaded layer, Equations (4) and (12) lead to Equation (13) and the amount-sensitivity, $S_{\mathrm{A}}$, should correlate with $1 / d$ as well:

$$
S_{\mathrm{A}}=\frac{\mathrm{d} R_{\mathrm{rel}}}{\mathrm{d} A} \approx \frac{\rho_{0} / \rho_{\mathrm{NOx}}-1}{d} \cdot \frac{\mathrm{d}\left(d_{\mathrm{NOx}}\right)}{\mathrm{d} A} \propto \frac{1}{d}
$$

As the resistivity decreases by at least one order upon saturation in $\mathrm{NO}_{\mathrm{x}},\left(\rho_{0} / \rho_{\mathrm{NOx}}-1\right) \geq 10$ and Equation (13) can be simplified to Equation (14):

$$
S_{\mathrm{A}}=\frac{\mathrm{d} R_{\mathrm{rel}}}{\mathrm{d} A} \approx \frac{\rho_{0}}{\rho_{\mathrm{NOx}}} \cdot \frac{1}{d} \cdot \frac{\mathrm{d}\left(d_{\mathrm{NOx}}\right)}{\mathrm{d} A} \propto \frac{1}{d}
$$

Since $S_{\mathrm{A}} \propto S_{\mathrm{c}}$ for constant gas flows, even the classical concentration-related sensitivity, $S_{\mathrm{c}}$, is expected to depend on $1 / d$ and to increase the thinner the sensing layers are.

This simplified model points out that the thickness of the sensitive layer might be an effective tool to vary the sensing properties (especially the sensitivity) of the accumulating $\mathrm{NO}_{\mathrm{x}}$ sensor. In the following study, the model was validated by exposing samples with various thicknesses to $\mathrm{NO}_{\mathrm{x}}$ containing gas flows and monitoring the sensing performance.

\section{Experimental}

Samples with coatings of different thicknesses were prepared and exposed to various gas compositions containing $\mathrm{NO}, \mathrm{NO}_{2}$ or total $\mathrm{NO}_{\mathrm{x}}$. As illustrated in Figure 1, the accumulating $\mathrm{NO}_{\mathrm{x}}$ sensor consists of an LNT layer (potassium-based LNT material provided by Johnson Matthey, composition details given in [30]) deposited on platinum interdigital electrodes (IDEs) with an area of $5 \times 6 \mathrm{~mm}^{2}$ and an electrode width and spacing of $100 \mu \mathrm{m}$ on an alumina substrate with a purity of 96\%. After drying and milling the catalyst powder, a screen-printable paste was made by adding organic additives (KD 2721, Zschimmer \& Schwarz). To obtain samples with sensitive layers in various thicknesses, the IDE area was screen-printed multiple times with the LNT-paste with intermediate drying periods. After firing at $650^{\circ} \mathrm{C}$ to remove organic additives, the sensing properties of the samples were analyzed at $380{ }^{\circ} \mathrm{C}$ in a sensor test bench. Thereby, lean measurements periods and rich desorption periods were periodically applied. The gas flow was kept constant at $\dot{V}(t)=2 \mathrm{~L} / \mathrm{min}$. The base lean gas consisted of $10 \% \mathrm{O}_{2}, 5 \% \mathrm{CO}_{2}$, and $50 \% \mathrm{~N}_{2}$ humidified (by a water bubbler at room temperature ) in $\mathrm{N}_{2}$, whereas the rich gas for regeneration contained $1.5 \% \mathrm{H}_{2}, 5 \%$ $\mathrm{CO}_{2}$, and $50 \% \mathrm{~N}_{2}$ humidified in $\mathrm{N}_{2}$. Different $\mathrm{NO}_{\mathrm{x}}$ gas compositions were admixed. The $\mathrm{NO}$ and $\mathrm{NO}_{2}$ concentrations were monitored by a chemiluminescence detector downstream of the sensor sample. The complex impedances of the sensitive devices were measured in the frequency range from $0.1 \mathrm{~Hz}$ to $20 \mathrm{MHz}$. The electrical characteristics of the bulk material can be described by an $R \| C$ parallel equivalent circuit. In time-continuous measurements, $R$ was calculated from the impedance taken at $1 \mathrm{kHz}$ applying the $R \| C$ model. The thicknesses of the sensitive layers were estimated using SEM micrographs. 


\section{Results and Discussion}

\subsection{Thickness Determination from SEM Analysis}

SEM images from the cross sections of the sensor samples printed multiple times with the LNT paste and an illustration for clarification reasons are shown in Figure 4. The microstructure of the sensitive layers is dominated by loose grains of different diameters. The thickness increased with each printing step from about $30 \mu \mathrm{m}$ (printed only once) to $150 \mu \mathrm{m}$ (printed five times). The samples printed four and five times had almost the same thickness. This might be due to a densification of the LNT material with successive printing as it is well known when printing porous films or due to a erroneous thickness determination as a result of the increased roughness. In general, the surface is very rough, with an increasing roughness in the case of thicker coatings lowering the accuracy of the thickness evaluation.

Figure 4. SEM analysis to estimate the thickness of the sensitive layers as a function of the number of prints.

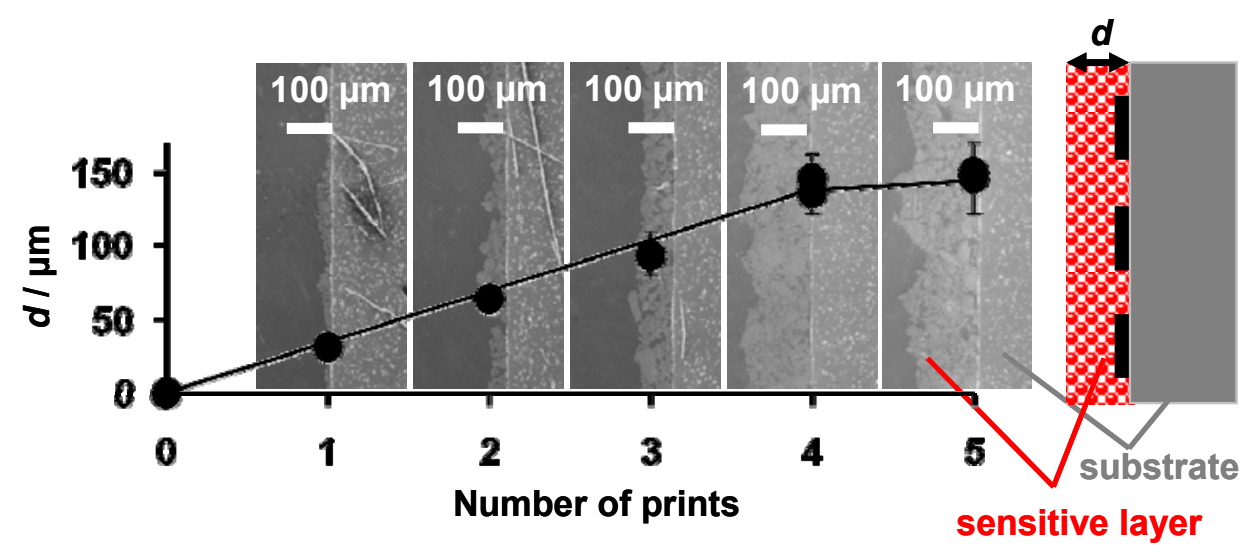

\subsection{Base Resistance as a Function of the Thickness}

As described above, the base resistance of the sensitive layer in the unloaded state, $R_{0}$, is expected to be proportional to $1 / d$ (Equation (10)). For an electrical characterization of the sensitive layer, complex impedance plots of the samples with sensitive LNT layers of 30 to $150 \mu \mathrm{m}$ were taken. The electrical properties of all investigated sensor samples between $10 \mathrm{~Hz}$ and $20 \mathrm{MHz}$ can be described by an $R \| C$ equivalent circuit. Figure 5(a) shows exemplarily Nyquist plots of samples with layers of 30, 60 , and $90 \mu \mathrm{m}$. The data points measured at $1 \mathrm{kHz}$ are marked. Fitting the spectra by an $R \| C$ model, the values of $R_{0}$ were obtained and are plotted as a function of $1 / d$ in Figure 5(b). $R_{0}$ increases with decreasing thickness, although no exact $1 / d$-dependency occurs. The resistances of the samples with the thinnest layers $(30 \mu \mathrm{m})$ are especially high, resulting in deviations from the expected $1 / d$-behavior (Equation (10)). This may be caused by the loose packing of the catalyst particles in the coating and by inaccuracies in the thickness estimation due to the film unevenness. Furthermore, the simple model depicted in Figure 3(a) that leads to Equation (10) is only valid if the layers are by far thinner than the distance between the IDE fingers $(d<<l$ '). This was confirmed in [28] by modeling the electrical flux lines in a system of a highly resistive substrate, metallic IDEs, and a resistive sensitive layer covering the IDEs. Since the distance between the electrodes of the applied IDE samples is $100 \mu \mathrm{m}$, it is 
assumed that in samples with coating of $100 \mu \mathrm{m}$ and above there are less flux lines in the outer LNT material. Therefore, the outer parts of the LNT layer do not or only slightly contribute to the overall resistance. As a result, these thicker films may no longer exhibit the $R_{0} \propto 1 / d$ behavior.

Figure 5. Effect of the thickness of the sensitive layer on the electrical properties in the unloaded state: (a) Complex impedance plots of samples with $30 \mu \mathrm{m}, 60 \mu \mathrm{m}$, and $90 \mu \mathrm{m}$ (data points at $1 \mathrm{kHz}$ are marked); (b) base resistance, $R_{0}$, as a function of the inverse thickness, $1 / d$.
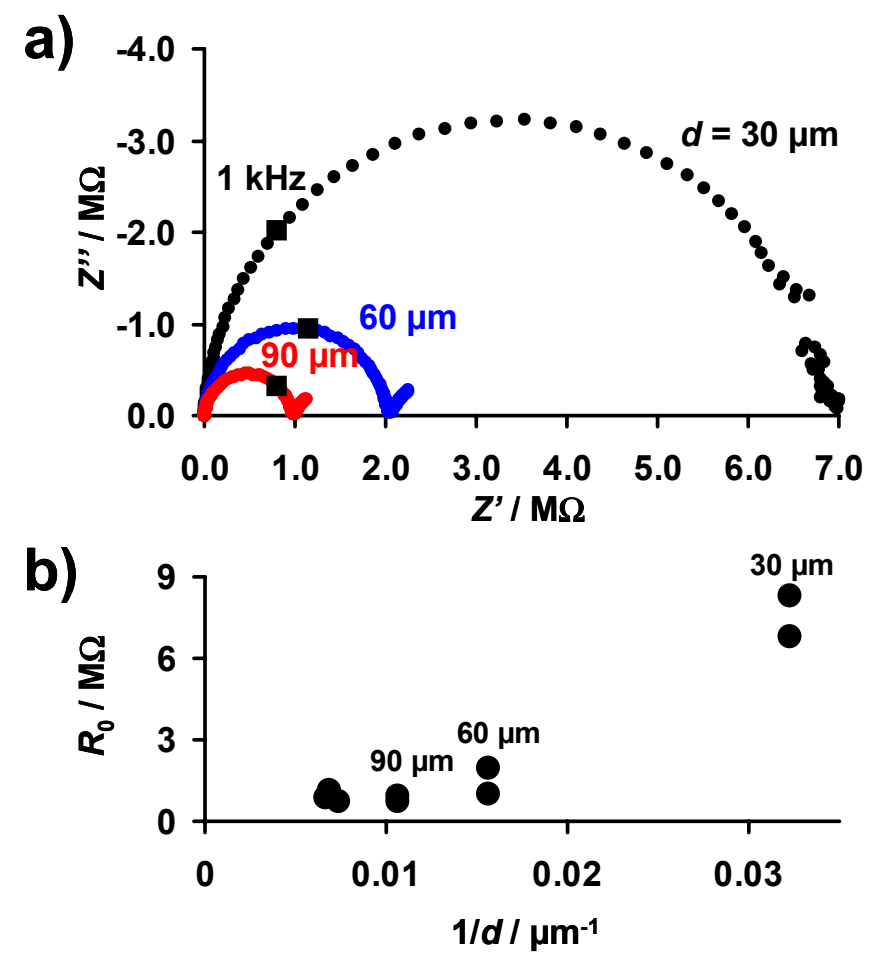

\subsection{Direct Accumulative Amount Detection}

A cyclic test program to investigate the accumulating sensing properties of the samples with various thicknesses in low levels of $\mathrm{NO}_{\mathrm{x}}$ (here $10 \mathrm{ppm}$ and less), especially the holding capability in the absence of $\mathrm{NO}_{\mathrm{x}}$, is given in Figure 6. Also shown is a comparison of the sensor responses, $R_{\text {rel }}$, towards $\mathrm{NO}$ and $\mathrm{NO}_{2}$. The samples with layers from 30 to $90 \mu \mathrm{m}$ were exposed to alternating $\mathrm{NO}$ and $\mathrm{NO}_{2}$ steps of $25 \mathrm{~s}$ with concentrations of 5 and $10 \mathrm{ppm}$ interrupted by $\mathrm{NO}_{\mathrm{x}}$ pauses of $200 \mathrm{~s}$. Due to the lower resistivity of the nitrate compared to the carbonate form of the storage material, the resistance decreased during $\mathrm{NO}_{\mathrm{x}}$ loading, yielding an increase in $R_{\text {rel }}[10,13]$. For all samples in Figure $6, R_{\text {rel }}$ increases linearly at constant $\mathrm{NO}_{\mathrm{x}}$ concentration, with an almost equal response to $\mathrm{NO}$ and $\mathrm{NO}_{2}$, while $R_{\text {rel }}$ remains constant in 0 ppm $\mathrm{NO}_{\mathrm{x}}$. It is evident that the sensors are less sensitive to $\mathrm{NO}_{\mathrm{x}}$ the thicker the storage layers are, albeit the samples are exposed to the same $\mathrm{NO}_{\mathrm{x}}$ profile. The constancy of $R_{\text {rel }}$ during the $200 \mathrm{~s}$ intervals without $\mathrm{NO}_{\mathrm{x}}$ reveals that all sensitive layers are able to keep the stepwise accumulated $\mathrm{NO}_{\mathrm{x}}$ molecules - even in the absence of $\mathrm{NO}_{\mathrm{x}}$. This indicates that the storage capacities of the samples with various thicknesses are not nearing saturation and that the formed nitrates are highly stable in the applied conditions enabling accumulating $\mathrm{NO}_{\mathrm{x}}$ sensing. Hence, all applied samples with various thicknesses provide accumulating $\mathrm{NO}_{\mathrm{x}}$ sensing properties. 
Figure 6. Accumulating sensor responses, $R_{\text {rel }}$, of the samples with various thicknesses increasing stepwise during cyclic exposure to 5 or $10 \mathrm{ppm} \mathrm{NO}$ (light grey line) or $\mathrm{NO}_{2}$ (dark grey line) for $25 \mathrm{~s}$ each alternating with $0 \mathrm{ppm} \mathrm{NO}_{\mathrm{x}}$ for $200 \mathrm{~s}$.

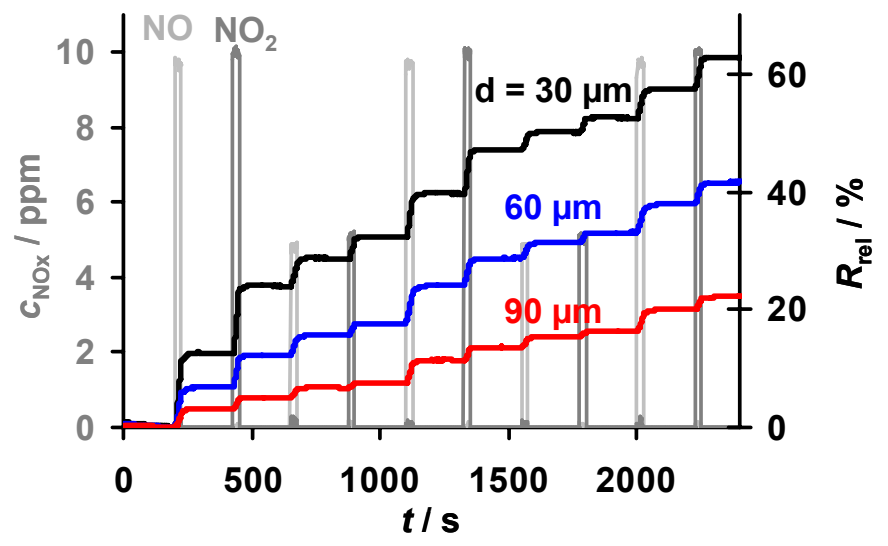

A more detailed analysis of the dependency of the sensitivity, the linear measurement range and the sensor response time on the thickness of the sensitive layer is given in the next sections.

\subsection{Concentration Detection by the Signal Derivative}

The progressive accumulation of $\mathrm{NO}_{\mathrm{x}}$ molecules in the sensitive layer in the presence of $\mathrm{NO}_{\mathrm{x}}$ enables the direct detection of the total $\mathrm{NO}_{\mathrm{x}}$ amount. As sketched in Figure 2, in the case of a constant flow rate, the time-based signal derivative, $\dot{R}_{\text {rel }}$ according to Equation (3), of the ideal accumulating sensor in the low loaded state can be applied to obtain information about the actual $\mathrm{NO}_{\mathrm{x}}$ concentration, $c_{\text {NOx }}$. To compare accumulating-type sensors with conventional gas sensors, one has to analyze the concentration sensitivity $S_{\mathrm{c}}$, i.e., the derivative $S_{c}=\mathrm{d} \dot{R}_{\text {rel }} / d_{c}$ according to Equation (5). Exemplarily, the corresponding data of the signal derivative $\dot{R}_{\text {rel }}$ of the sample coated with a $30 \mu \mathrm{m}$ storage layer are plotted in Figure 7(a). During the first four $\mathrm{NO}_{\mathrm{x}}$ periods, $\dot{R}_{\text {rel }}$ reflects the curve of $c_{\mathrm{NOx}}$ being the sum of $c_{\mathrm{NO}}$ and $c_{\mathrm{NO} 2}$ allowing for determining the actual $\mathrm{NO}_{\mathrm{x}}$ concentration. The corresponding characteristic line for the concentration detection correlating $\dot{R}_{\text {rel }}$ and $c_{\text {NOx }}$ is given in Figure $7(\mathrm{~b}) . \dot{R}_{\text {rel }}$ increases with an increased $\mathrm{NO}_{\mathrm{x}}$ concentration in the gas. Hence, the $\mathrm{NO}_{\mathrm{x}}$ sensitivity, $S_{\mathrm{c}}$, of the $30 \mu \mathrm{m}$ sample can be calculated from Equation (5) and was found to be $0.049 \% / \mathrm{ppm} \cdot \mathrm{s}$. This means that the resistance decreases by $0.049 \% / \mathrm{s}$ upon exposure to $1 \mathrm{ppm} \mathrm{NO}_{\mathrm{x}}$. The analysis of the sensor response times for the concentration detection by $\dot{R}_{\text {rel }}$ in dependency of the thickness of the sensitive layer will be discussed in detail in Sections 5 and 6 . From $\dot{R}_{\text {rel }}$ in Figure 7, one obtains a sensor response and recovery time of about 5 to $8 \mathrm{~s}$, which is in the range of the gas exchange time of the setup. Figure 7 demonstrates that besides detecting directly the total $\mathrm{NO}_{\mathrm{x}}$ amount, the signal derivative of the accumulating $\mathrm{NO}_{\mathrm{x}}$ sensor allows $\mathrm{NO}_{\mathrm{x}}$ concentration monitoring with a high sensitivity and a fast sensor response. 
Figure 7. Signal derivative, $\dot{R}_{\text {rel }}$, of the $30 \mu \mathrm{m}$ sample during cyclic exposure to NO and $\mathrm{NO}_{2}$ : (a) $\dot{R}_{\text {rel }}$ of the $30 \mu \mathrm{m}$ sample corresponding with the actual $\mathrm{NO}_{\mathrm{x}}$ concentration, $c_{\mathrm{NO}}$; (b) resulting correlation between $\dot{R}_{\text {rel }}$ and $c_{\mathrm{NOx}}$.
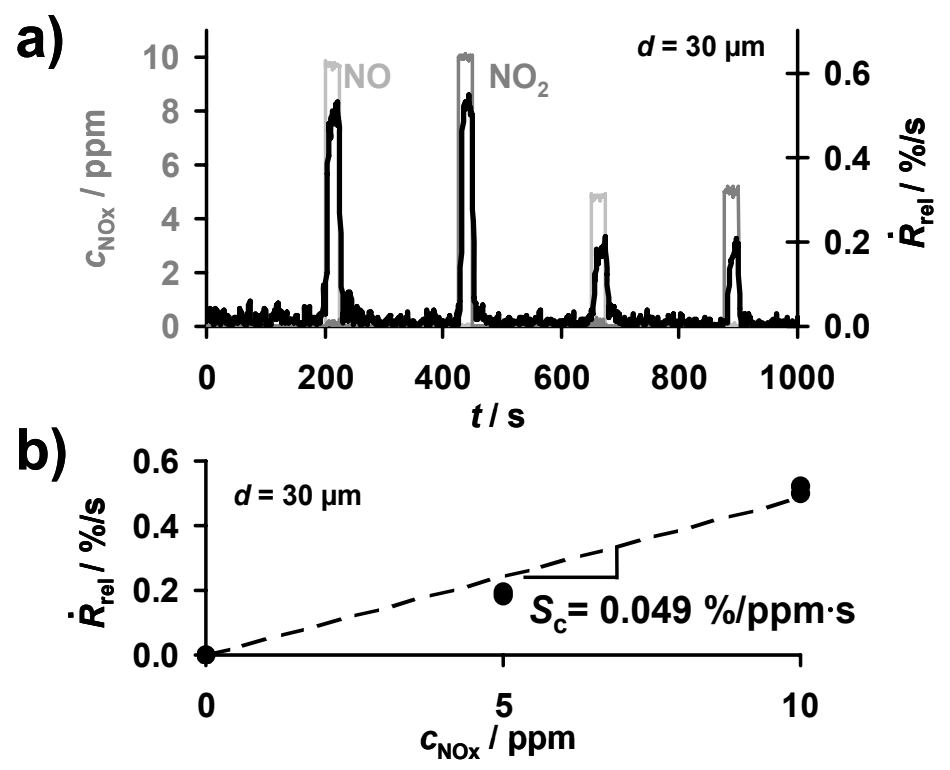

\subsection{The Effect of the Thickness on the Sensitivity}

According to the simplified model that is based on the assumption that a thin nitrate layer forms at the surface of the sensitive storage layer upon $\mathrm{NO}_{\mathrm{x}}$ exposure, as shown in Figure 3, and the resulting Equation (13), both sensitivities, $S_{\mathrm{A}}$ and $S_{\mathrm{c}}$, should increase with $1 / d$. The characteristic lines, correlating $R_{\text {rel }}$ with the total $\mathrm{NO}_{\mathrm{x}}$ amount, $A$, extracted from the cyclic measurement data presented in Figure 6 are shown in Figure 8(a). For each sample, the data points of $R_{\text {rel }}$ measured at the end of each $\mathrm{NO}_{\mathrm{x}}$ step form straight lines through the origin up to a sensor response of about $30 \%$, independent of the $\mathrm{NO}_{\mathrm{x}}$ concentration or the type of $\mathrm{NO}_{\mathrm{x}}\left(\mathrm{NO}\right.$ or $\left.\mathrm{NO}_{2}\right)$. Comparing the characteristic lines for the amount detection of the samples with different thicknesses in Figure 8(a), it becomes clear that $S_{\mathrm{A}}$ decreases when the sensitive layer gets thicker. To evaluate the thickness effect in detail, $S_{\mathrm{A}}$ is plotted as a function of $1 / d$ in Figure $8(\mathrm{~b}) . S_{\mathrm{A}}$ increases linearly with $1 / d$ with small deviations in the case of layers being $90 \mu \mathrm{m}$ or thicker $\left(1 / d \leq 0.011 \mu \mathrm{m}^{-1}\right)$.

From the concentration related sensitivity $S_{\mathrm{c}} \approx 0.049 \% / \mathrm{ppm} \cdot \mathrm{s}$ of the $30 \mu \mathrm{m}$ sample determined from Figure 7(b) and the applied gas flow of $\dot{V}=2 \mathrm{~L} / \mathrm{min}=0.033 \mathrm{~L} / \mathrm{s}$, the sensitivity $\mathrm{S}_{\mathrm{A}}$ can be calculated. Applying the relationship between $S_{\mathrm{A}}$ and $S_{\mathrm{c}}$ described by Equation (7) one obtains $S_{\mathrm{A}} \approx 1.48 \% / \mu \mathrm{L}$, which agrees with the value shown in Figure 8(b) for the $30 \mu \mathrm{m}$ sample. This good agreement verifies that validity of the correlation between $S_{\mathrm{A}}$ and $S_{\mathrm{c}}$ (Equation (7)).

These results verify the simplified model as illustrated in Figure 3 and demonstrate that the thickness of the accumulating $\mathrm{NO}_{\mathrm{x}}$ storage layer can be used as an effective tool to adapt the sensor sensitivity to the application requirements.

According to Equation (14) a linear correlation between $S_{\mathrm{A}}$ and $1 / d$ with a proportionality factor of $\rho_{0} / \rho_{\mathrm{NOx}} \cdot \mathrm{d}\left(d_{\mathrm{NOx}}\right) / \mathrm{d} A$ can be expected from the simplified model. Hence, applying the slope of the correlation in Figure $8(\mathrm{~b}), \mathrm{d} S / \mathrm{d}(1 / d)$, the thickness of the formed nitrate layer, $d_{\mathrm{NOx}}$, dependent on the exposed amount of $\mathrm{NO}_{\mathrm{x}}$ can be estimated. Since the resistivity of the samples was found to decrease by 
at least one order upon saturation in $\mathrm{NO}_{\mathrm{x}}$ (result not shown here), $\rho_{0} / \rho_{\mathrm{NOx}} \approx 10$ is assumed as a minimal value. With the slope $\mathrm{d} S / \mathrm{d}(1 / d)$ being $0.43 \mu \mathrm{m} / \mu \mathrm{L}$ (dotted line in Figure 8(b) for samples $<100 \mu \mathrm{m}$ ), $d_{\text {NOx }}$ increases by less than about $43 \mathrm{~nm}$ per $\mu \mathrm{L} \mathrm{NO}_{\mathrm{x}}$ in the gas phase.

Figure 8. Layer thickness influence on the sensitivity: (a) Comparison of the characteristic lines for different coating thicknesses; (b) the resulting values of the amount-sensitivity, $S_{\mathrm{A}}$, as a function of $1 / d$.
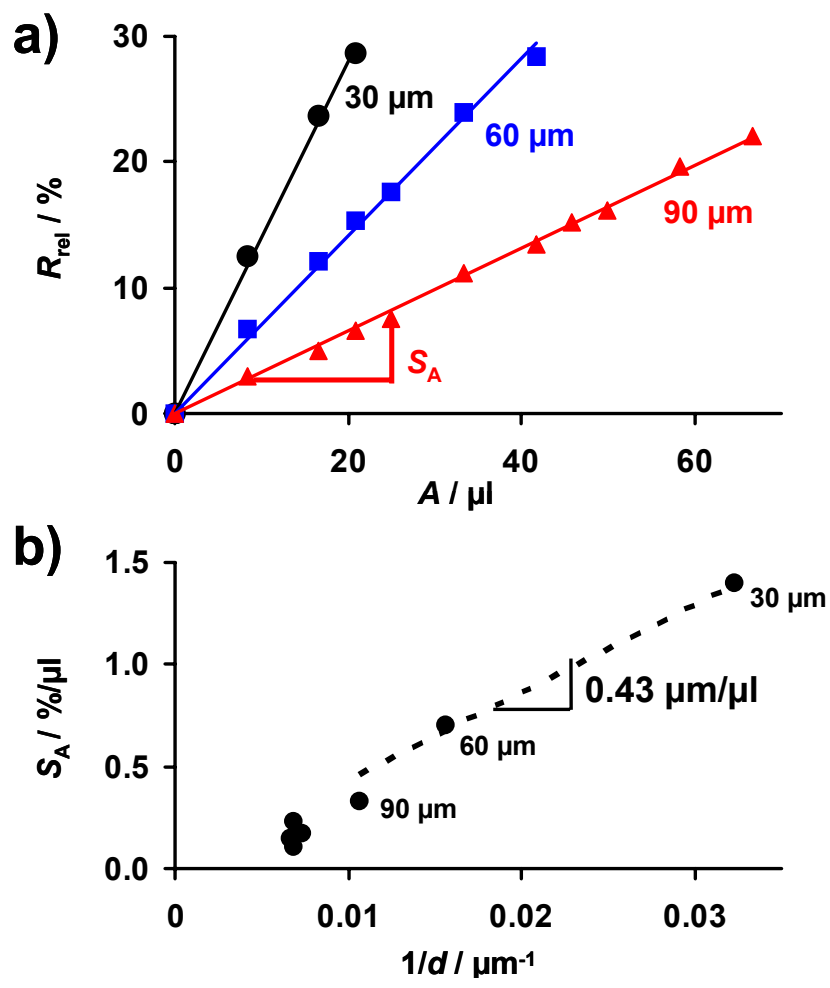

\subsection{Variations of the Linear Measurement Range}

As sketched in Figure 2, the linear measurement range, $L M R$, is defined as the amount of $\mathrm{NO}_{\mathrm{x}}$ that can be detected when a linear correlation between $R_{\text {rel }}$ and $A$ exists. The $L M R$ ends when saturation effects occur and the sensitivities $S_{\mathrm{A}}$ and $S_{\mathrm{c}}$ decrease. Therefore, besides the sensitivity and the sensor response time, the $L M R$ is an important feature of the accumulating-type sensor. The effect of the sensitive layer thickness on the $L M R$ is addressed in Figure 9. In the presence of $10 \mathrm{ppm} \mathrm{NO}_{\mathrm{x}}$ (consisting of $5 \mathrm{ppm} \mathrm{NO}$ and $5 \mathrm{ppm} \mathrm{NO}_{2}$ ) in a lean gas mixture, $R_{\text {rel }}$ of all samples increases continuously with time (Figure 9(a)). In accordance to Equation (14), the sensitivity is higher in the case of thinner sensitive storage layers. From Figure 9(a) it seems that, independent on the sensitive layer thickness, the $L M R$ ends at about $R_{\text {rel }}=30 \%$. This results in an increase of the $L M R$-amount with the layer thickness as shown in Figure 9(b). The slope in Figure 9(b) indicates that $0.80 \mu \mathrm{L} \mathrm{NO}_{\mathrm{x}}$ can be detected linearly per $\mu \mathrm{m}$ LNT layer deposited on the sensor. 
Figure 9. The effect of the thickness on the linear measurement range, $L M R$ : (a) $R_{\text {rel }}$ increases linearly in the presence of 5 ppm NO and 5 ppm $\mathrm{NO}_{2}$ up to about $30 \%$, (b) $L M R$ as a function of $d$.

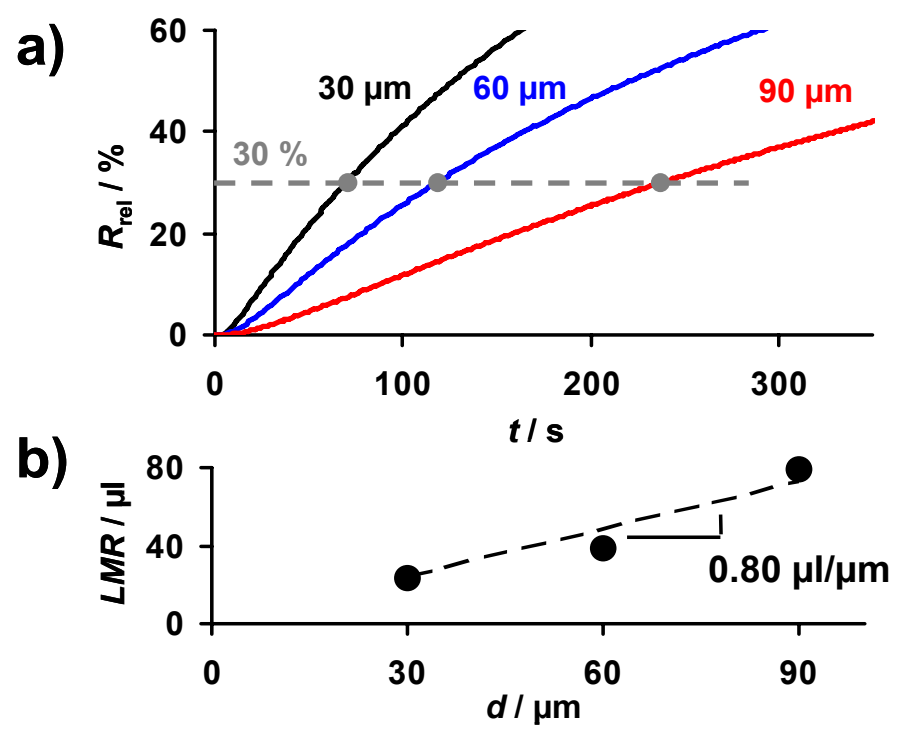

In Section 5.5, it was calculated that the thickness of the nitrate fraction of the sensitive layer increases by about $43 \mathrm{~nm} / \mu \mathrm{L}$. This value can be combined with the dependency of the $L M R$ on $d$ of $0.80 \mu \mathrm{L} / \mu \mathrm{m}$ from Figure 9(b). One obtains that if reaching the end of the linear measurement range upon $\mathrm{NO}_{\mathrm{x}}$ exposure $43 \mathrm{~nm} / \mu \mathrm{L} \cdot 0.80 \mu \mathrm{L} / \mu \mathrm{m}=34 \mathrm{~nm}$ nitrate is formed per $\mu \mathrm{m}$ LNT material. In other words, independent of the LNT thickness only about 3\% of the sensitive material is converted to nitrate in the case of $\mathrm{NO}_{\mathrm{x}}$ storage in the linear measurement range. This estimated nitrate fraction of the sensitive layer is much less than the values reported for the storage sites utilization of LNT catalysts of maximal 20 to $40 \%$ upon saturation [23-25]. This difference indicates that the end of the linear measurement range of the accumulating $\mathrm{NO}_{\mathrm{x}}$ sensor might be limited rather by the non-linear relation between resistivity change and $\mathrm{NO}_{\mathrm{x}}$ loading than by the storage capacity of the LNT material.

\subsection{Evaluation of the Sensor Response Time}

With the accumulating $\mathrm{NO}_{\mathrm{x}}$ sensor the amount of $\mathrm{NO}_{\mathrm{x}}$ is detected by looking on the changes in the electrical properties and not on the equilibrium values like with conventional gas sensors. Hence, no sensor response time of $R_{\text {rel }}$ can be defined in the classical way. Instead one has to apply the timely derivative, $\dot{R}_{\text {rel }}$, which is a function of the concentration and therefore corresponds to the sensor signal of conventional gas sensors. From the measured data of the samples in $10 \mathrm{ppm} \mathrm{NO}_{\mathrm{x}}$, the sensor response time of the slope $\dot{R}_{\text {rel }}$ was analyzed. Therefore, the time to reach $90 \%$ of the maximum value of $\dot{R}_{\text {rel }}, t_{90}$, is compared for the samples with different coating thicknesses. Figure 10 shows that $t_{90}$ increases with $d$. While $t_{90}$ of the sample with a $30 \mu \mathrm{m}$ storage layer is about $7 \mathrm{~s}$, it is in the range of $30 \mathrm{~s}$ in the case of the $90 \mu \mathrm{m}$ sample. In the case of very thin coatings the sensor response is limited by the gas exchange of the test bench, which is in the range of $7 \mathrm{~s}$. For very thick coatings $(d \approx l), \mathrm{NO}_{\mathrm{x}}$ storage occurs in a region far away from the electrodes. Due to the increasingly weaker electrical field lines, $\mathrm{NO}_{\mathrm{x}}$ uptake in this region of the LNT layer is most probably not reflected properly by $R_{\text {rel }}$ and 
$\dot{R}_{\text {rel }}$. Additionally, it is expected that the accessibility of the storage sites is dependent on the LNT thickness as with progressive $\mathrm{NO}_{\mathrm{x}}$ loading upcoming $\mathrm{NO}_{\mathrm{x}}$ molecules need to diffuse into the catalyst material to reach unoccupied storage sites [26,27,31]. The analysis of the sensitivity and the sensor response time in Figures 8 and 10 clarifies that for a highly sensitive and fast low level detection of $\mathrm{NO}_{\mathrm{x}}$, accumulating $\mathrm{NO}_{\mathrm{x}}$ sensors with a thin sensitive layer are preferable.

Figure 10. Analysis of the sensor response time, $t_{90}$, of $\dot{R}_{\text {rel }}$ in $10 \mathrm{ppm} \mathrm{NO}$ as a function of the thickness $d$.

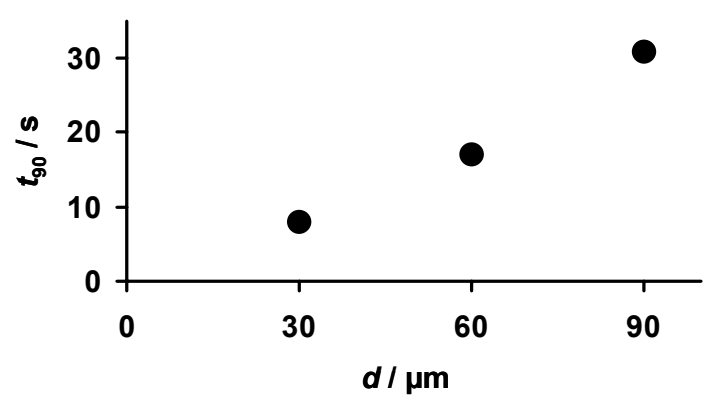

\section{Conclusions}

The intent of this study was to investigate the influence of the sensitive layer thickness on the sensing properties of the accumulating $\mathrm{NO}_{\mathrm{x}}$ sensor. In several $\mathrm{NO}_{\mathrm{x}}$ loading experiments it was demonstrated that the general accumulating $\mathrm{NO}_{\mathrm{x}}$ amount sensing properties seem not to be affected by the thickness of the sensitive layer in the studied range (i.e., the increase of the sensor signal in the presence of $\mathrm{NO}_{\mathrm{x}}$ due to $\mathrm{NO}_{\mathrm{x}}$ accumulation, the correlation between the slope and the $\mathrm{NO}_{\mathrm{x}}$ concentration, and the constancy of the sensor signal in the $\mathrm{NO}_{\mathrm{x}}$ absence due to the strength of sorption). The linearity of the sensor signal, $R_{\text {rel }}$, with the total $\mathrm{NO}_{\mathrm{x}}$ amount enables the detection of the actual $\mathrm{NO}_{\mathrm{x}}$ concentration by $\dot{R}_{\text {rel }}$ with all applied samples.

Figure 11. Illustration of the effect of the thickness of the sensitive layer $\left(d_{1}<d_{2}\right)$ on the sensitivity, $S_{\mathrm{A}}$, and the linear measurement range, $L M R$, with the end of the linear measurement range being at $30 \%$ signal change.

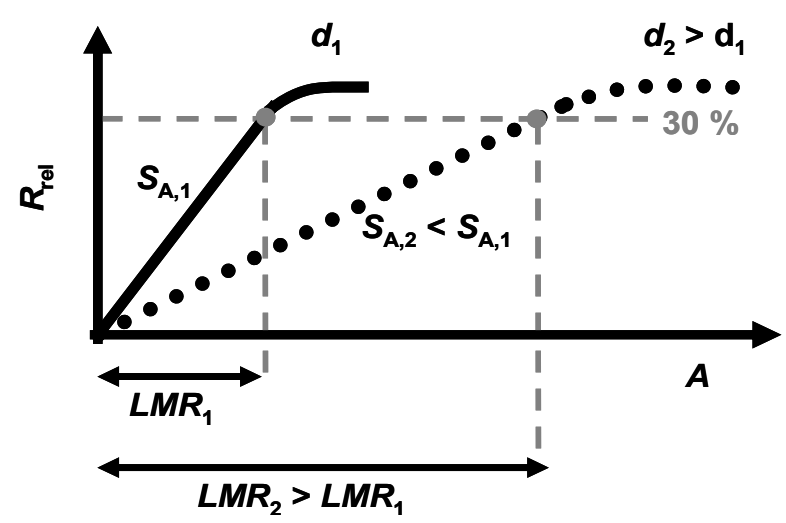

However, like the base resistance, the sensitivity to $\mathrm{NO}_{\mathrm{x}}$ is inversely proportional to the film thickness $d$. This agrees with a simple model concerning nitrate formation at the surface of the sensitive layer. It was demonstrated that $\mathrm{NO}_{\mathrm{x}}$ can be detected linearly until the sensor resistances 
reaches about 30\%. This limit was found to be independent on the thickness of the sensitive layer. This controversial effect of the sensitive layer thickness on the sensitivity, $S_{\mathrm{A}}$ (and also on $S_{\mathrm{c}}$ ), and on the linear measurement range, $L M R$, is illustrated in Figure 11 for two samples with two different thicknesses, $d_{2}$ (dark grey line) being higher than $d_{1}$ (light grey line). While $S_{1}$ is higher than $S_{2}$, the resulting $L M R_{2}$ is larger than $L M R_{1}$. More particularly, $L M R$ increases with $d$ allowing for a measurement range adaption depending on the requirements of the application conditions. However, there is a trade-off between a large linear measurement range and a high sensitivity.

The presented measurement results also point out that the timely sensor response characteristic depends on the thickness of the storage material. In the case of very thin layers $(30 \mu \mathrm{m})$ the sensor response time corresponds to the gas exchange time of the gas flow stand, whereas the sensor signal becomes slower as the thickness increases. An estimation based on the presented simplified model of the sensor setup reveals that, independently on the thickness of the LNT material only a small fraction of the sensitive layer - probably about 3\%-is involved in the $\mathrm{NO}_{\mathrm{x}}$ storage process as the accumulating sensor is operated in the linear measurement range.

\section{Acknowledgements}

The authors gratefully acknowledge the LNT material preparation by Shadab Mulla, Todd H. Ballinger, Hai-Ying Chen (Johnson Matthey) and the SEM analysis by Angelika Mergner (Lehrstuhl Funktionsmaterialien). Ralf Moos thanks the German Research Foundation (DFG) for supporting this work under grant number MO 1060/15-1. This publication was funded by the German Research Foundation (DFG) and the University of Bayreuth in the funding program "Open Access Publishing”.

\section{References}

1. Afzal, A.; Cioffi, N.; Sabbatini, L.; Torsi, L. $\mathrm{NO}_{\mathrm{x}}$ sensors based on semiconducting metal oxide nanostructures: Progress and perspectives. Sens. Actuators B Chem. 2012, 171-172, 25-42.

2. Kim, Y.-W.; van Nieuwstadt, M. Threshold Monitoring of Urea SCR Systems; SAE Technical Paper 2006-01-3548; SAE 2006 Commercial Vehicle Engineering Congress \& Exhibition: Rosemont, IL, USA, October 2006.

3. Sasaki, H.; Scholl, D.; Parsons, M.; Inagaki, H.; Shiotani, K.; Visser, J.; Zawacki, G.; Kawai, T.; Teramoto, S.; Kubinski, D. Development of an $\mathrm{Al}_{2} \mathrm{O}_{3} / \mathrm{ZrO}_{2}$-Composite High-Accuracy $\mathrm{NO}_{x}$ Sensor; SAE Technical Paper 2010-01-0041; SAE 2010 World Congress \& Exhibition: Detroit, MI, USA, April 2010.

4. Directive 2008/50/EC of the European Parliament and of the Council of 21 May 2008 on Ambient Air Quality and Cleaner Air for Europe; Official Journal of the European Union, 2008; L152/1.

5. Alkemade, U.G.; Schumann, B. Engines and exhaust after treatment systems for future automotive applications. Solid State Ionics 2006, 177, 2291-2296.

6. Twigg, M.V. Progress and future challenges in controlling automotive exhaust gas emissions. Appl. Catal. B Environ. 2007, 70, 2-15.

7. Padilla, M.; Perera, A.; Montoliu, I.; Chaudry, A.; Persaud, K.; Marco, S. Drift compensation of gas sensor array data by orthogonal signal correction. Chemometr. Intell. Lab. Syst. 2010, 100, $28-35$. 
8. Sickles, J.E.; Grohse, P.M.; Hodson, L.L.; Salmons, C.A.; Cox, K.W.; Turner, A.R.; Estes, E.D. Development of a method for the sampling and analysis of sulfur dioxide and nitrogen dioxide from ambient air. Anal. Chem. 1990, 62, 338-346.

9. Varshney, C.K.; Singh, A.P. Passive samplers for $\mathrm{NO}_{\mathrm{x}}$ monitoring: A critical review. Environmentalist 2003, 23, 127-136.

10. Groß, A.; Beulertz, G.; Marr, I.; Kubinski, D.J.; Visser, J.H.; Moos, R. Dual mode $\mathrm{NO}_{\mathrm{x}}$ sensor: Measuring both the accumulated amount and instantaneous level at low concentrations. Sensors 2012, 12, 2831-2850.

11. Beulertz, G.; Groß, A.; Moos, R.; Kubinski, D.J.; Visser, J.H. Determining the total amount of $\mathrm{NO}_{\mathrm{x}}$ in a gas stream-Advances in the accumulating gas sensor principle. Sens. Actuators $B$ Chem. 2012, doi:10.1016/j.snb.2012.02.017.

12. Moos, R.; Wedemann, M.; Spörl, M.; Reiß, S.; Fischerauer, G. Direct catalyst monitoring by electrical means: An overview on promising novel principles. Top. Catal. 2009, 52, 2035-2040.

13. Fremerey, P.; Reiß, S.; Geupel, A.; Fischerauer, G.; Moos, R. Determination of the $\mathrm{NO}_{\mathrm{x}}$ loading of an automotive lean $\mathrm{NO}_{\mathrm{x}}$ trap by directly monitoring the electrical properties of the catalyst material itself. Sensors 2011, 11, 8261-8280.

14. Moos, R.; Zimmermann, C.; Birkhofer, T.; Knezevic, A.; Plog, C.; Busch, M.R.; Ried, T. Sensor for Directly Determining the State of a No Storage Catalyst; SAE Technical Paper 2008-01-0447; SAE World Congress \& Exhibition: Detroit, MI, USA, April 2008; doi:10.4271/2008-01-0447.

15. Groß, A.; Bishop, S.R.; Yang, D.J.; Tuller, H.L.; Moos, R. The electrical properties of $\mathrm{NO}_{\mathrm{x}}$-storing carbonates during $\mathrm{NO}_{\mathrm{x}}$ exposure. Solid State Ionics 2012, doi:10.1016/j.ssi.2012.05.009.

16. Morrison, S.R.; Madou, M.J. Chemical Sensing with Solid State Devices; Academic Press Inc.: London, UK, May 1989.

17. Epling, W.S.; Campbell, L.E.; Yezerets, A.; Currier, N.W.; Parks, J.E., II. Overview of the fundamental reactions and degradation mechanism of $\mathrm{NO}_{\mathrm{x}}$ storage/reduction catalysts. Catal. Rev. 2004, 46, 163-245.

18. Roy, S.; Baiker, A. $\mathrm{NO}_{\mathrm{x}}$ storage-reduction catalysis: From mechanism and materials properties to storage-reduction performance. Chem. Rev. 2009, 109, 4054-4091.

19. Liu, G.; Gao, P.-X. A review of $\mathrm{NO}_{\mathrm{x}}$ storage/reduction catalysts: Mechanism, materials and degradation studies. Catal. Sci. Technol. 2011, 1, 552-568.

20. Lesage, T.; Saussey, J.; Malo, S.; Hervieu, M.; Hedouin, C.; Blanchard, G.; Daturi, M. Operando FTIR study of $\mathrm{NO}_{x}$ storage over a $\mathrm{Pt} / \mathrm{K} / \mathrm{Mn} / \mathrm{Al}_{2} \mathrm{O}_{3}-\mathrm{CeO}_{2}$ catalyst. Appl. Catal. B Environ. 2007, 72, 166-177.

21. Geupel, A.; Schönauer, D.; Röder-Roith, U.; Kubinski, D.J.; Mulla, S.; Ballinger, T.H.; Chen, H.-Y.; Visser, J.H.; Moos, R. Integrating nitrogen oxide sensor: A novel concept for measuring low concentrations in the exhaust gas. Sens. Actuators B Chem. 2010, 145, 756-761.

22. Geupel, A.; Kubinski, D.J.; Mulla, S.; Ballinger, T.H.; Chen, H-Y.; Visser, J.H.; Moos, R. Integrating $\mathrm{NO}_{\mathrm{x}}$ sensor for automotive exhausts-A novel concept. Sens. Lett. 2011, 9, 311-315.

23. Castoldi, L.; Lietti, L.; Forzatti, P.; Morandi, S.; Ghiotti, G.; Vindigni, F. The $\mathrm{NO}_{\mathrm{x}}$ storage-reduction on $\mathrm{Pt}-\mathrm{K} / \mathrm{Al}_{2} \mathrm{O}_{3}$ lean $\mathrm{NO}_{\mathrm{x}}$ trap catalyst. J. Catal. 2010, 276, 335-350. 
24. Muncrief, R.L.; Khanna, P.; Kabin, K.S.; Harold, M.P. Mechanistic and kinetic studies of $\mathrm{NO}_{\mathrm{x}}$ storage and reduction on $\mathrm{Pt} / \mathrm{BaO} / \mathrm{Al}_{2} \mathrm{O}_{3}$. Catal. Today 2004, 98, 393-402.

25. Scholz, C.M.L.; Gangwal, V.R.; de Croon, M.H.J.M.; Schouten, J.C. Influence of $\mathrm{CO}_{2}$ and $\mathrm{H}_{2} \mathrm{O}$ on $\mathrm{NO}_{\mathrm{x}}$ storage and reduction on a $\mathrm{Pt}-\mathrm{Ba} / \gamma-\mathrm{Al}_{2} \mathrm{O}_{3}$ catalyst. Appl. Catal. B Environ. 2007, 71, $143-150$.

26. Tuttlies, U.; Schmeißer, V.; Eigenberger, G. A mechanistic simulation model for $\mathrm{NO}_{\mathrm{x}}$ storage catalyst dynamics. Chem. Eng. Sci. 2004, 59, 4731-4738.

27. Olsson, L.; Blint, R.J.; Fridell, E. Global kinetic model for lean $\mathrm{NO}_{\mathrm{x}}$ traps, Ind. Eng. Chem. Res. 2005, 44, 3021-3032.

28. Hagen, G. Impedimetric Zeolite-Based Gas Sensors. Ph.D. Dissertation, Universität Bayreuth, Bayreuth, Germany, 2009.

29. Schönauer, D.; Moos, R. Detection of water droplets on exhaust gas sensors. Sens. Actuators $B$ Chem. 2010, 148, 624-629.

30. Chen, H.-Y.; Mulla, S.; Ballinger, T.H. $\mathrm{No}_{\mathrm{x}}$ Storage Materials for Sensor Applications, U.S. Patent 20,100,146,935, 17 June 2010.

31. Rettig, F.; Moos, R.; Plog, C. Sulfur adsorber for thick-film exhaust gas sensors. Sens. Actuators $B$ Chem. 2003, 93, 36-42.

(C) 2012 by the authors; licensee MDPI, Basel, Switzerland. This article is an open access article distributed under the terms and conditions of the Creative Commons Attribution license (http://creativecommons.org/licenses/by/3.0/). 